\title{
REVIEW
}

\section{KNOWLEDGE PRODUCTION IN TOURISM: THE EVALUATION OF CONTEXTUAL LEARNING PROCESSES IN DESTINATION STUDIES}

\author{
ARIANE PORTEGIES, THEO DE HAAN, and VINCENT PLATENKAMP \\ NHTV Breda University of Applied Sciences, Breda, The Netherlands
}

\begin{abstract}
In this review article, the reviewers argue that the field of Tourism Management/Tourism Studies requires a more decided contextual approach in order to handle the growing complexity of "knowledge production" in international research and education needs in and around tourism development. Portegies, de Haan, and Platenkamp maintain that-in a network society where different types of society interfere with one another-complex contextual learning processes take place that are not taken into account seriously enough within the education and research milieux of the field. At NHTV Breda University of Applied Sciences (in the Netherlands), a curriculum for higher education has emerged through the years that attempts (mainly in Southeast Asia) to incorporate these sorts of learning processes in various cross-cultural environments. Over the years, there, an originally "more instrumental approach" to destination analysis has changed into a contextual one in which participants have become much more sensitive in their capacity to receive and understand the perspectives of found stakeholders at particular international tourism destinations. This contextual approach is now evaluated (within this review article) in comparison to the aforesaid previously dominant instrumental approach to the production of knowledge about destinations. It does so by addressing to the important distinction between mode 1 and 2 knowledge production (after Gibbons et al.) and by adding assessments built around a mode 3 type of knowledge production (following Kunneman), which relates to normative and existential awarenesses. Readers of Tourism Analysis are invited to comment on the observations of Portegies, de Haan, and Platenkamp, in terms of the fit of contextual learning processes in other parts of the world or otherwise with regard to the relevance of mode $1 / 2 / 3$ sorts of knowledge production to Tourism Management/ Tourism Studies. Short critiques of 1,000 words (maximum) on either of these subjects should be sent to the Review Editor of Tourism Analysis at khdeva@btopenworld.com. [Review Editor's abstract]
\end{abstract}

Key words: Contextual learning process; Changing perspectives; Tourism destinations; Modes 1, 2, and 3 of knowledge production; Vietnam; Cambodia; Bali

Address correspondence to Dr. Vincent Platenkamp, Associate Professor, Centre for Cross-cultural Understanding, NHTV Breda University of Applied Sciences, Breda, The Netherlands. Tel: 0031(0)76-5332236; Fax: 0031(0)76-5332295; E-mail: Platenkamp.v@ nhtv.nl 


\section{Introduction}

The pursuit of knowledge production in tourism has created an international marketplace for higher education institutions in the centres of our network-society (Castells, 2000). Networks within but also outside these societies change all the time. The international classroom is situated in these networks. When networks change, the members of these networks change too. Therefore, important trends such as the tension between the global and the local, the colonization of the lifeworld and the role of experts in this context, and postcolonialism also enter the international classroom via students and teachers from all over the globe.

An obvious characteristic of international education stems from the fact that it (still) is predominantly situated in the richer part of the world, in Europe, North America, and Australasia. This implies that in relation to these important trends the Western international classroom occupies a powerful position in the power-knowledge constellation of this field. This mostly implies a subaltern position for the "rest of the academic world," which needs some fundamental reflection. The examples are not always easy to understand. In the tension between the global and the local many students from China or Africa strive for clear and instrumental knowledge from the predominant management and marketing education in the "modern" West. Once they return home in their expected modernizing networks, they may want to implement this instrumental "Western knowledge" in the process of modernization of their local situations. Within this search for knowledge the growing dominance of an instrumentalist Expertenkultur, such as it has been criticized (Foucault, 1977; Habermas, 1982), will expand its pressure on the demand for instrumental knowledge in the international classroom.

International students come from everywhere and for a variety of reasons. Some American students choose continental Europe in order to experience their "Grand Tour" through Europe and do some studies at the same time to satisfy their home front. Some French students come to The Netherlands because of its famous drugs policy. Chinese students choose continental Europe because the fees for British education are too high for them.
At the same time, there is a tendency of universities in the US and the UK to further raise the fees for foreign students in order to get the most talented ones. In that sense, a global war for talent seems to be on its way: universities can earn more money - with higher fees than for their home students-from foreign students, who want to have a better education than in their home countries. Obviously, students also have strategic reasons to enter the international classroom that stem from the various institutional contexts and varying networks they come from. Certainly, they do not just visit the academic institution itself, but the whole economical, political, and cultural context in which the international classroom is embedded. In a narrative approach like in Murphy-Lejeune (2002) the rich context of these students becomes clear. It is the first narrative in-depth analysis of the situation of international students and deserves the utmost attention of those who want to use this situation in the design of their international curriculum. More studies like this are needed to understand the global and local contexts in which education takes place.

At the same time international education promises students a better destiny. This promise in many cases seems to be conceived of from a highly instrumentalist point of view. Students often are attracted by postgraduate courses that concentrate on marketing or management, also of tourism products and destinations. Originally this was, in 1992, also the intention of the ITMC (International Tourism and Management Consultancy, BA in Breda) program that will be discussed in this review article. Students should become skilled consultants or managers in international tourism destinations. In order to reach this goal they should learn how to study tourism impacts or use a "destination mix" in order to come to good advice for decisions in the international tourism practice. The approach was instrumentalist from the start.

However, in this review article a perspective will be presented that tries to look beyond this instrumentalist perspective of solving the problems that are facing international tourism and education (cf. Hollinshead, 2007). This noninstrumentalist perspective is embedded in the same type of network society as its instrumentalist opponent and 
has to deal with that as well. It departs from a different view on international education, though. It remains crucial to stress the fact that this contextual approach grew gradually within the limits of a tourism practice in higher education. At its start it was instrumentalist in outline. There was no "blueprint" of how this practice should be directed in the best possible manner. Step by step, in an "incremental" way, gradually an educational practice developed that afterwards can best be characterized by a "contextual practice" of higher education. In contextual education contextual information is searched for and used from all the stakeholders involved. For example, research by students in Vietnam showed that the layout of a hotel had to be adapted because of the construction of a road along its waterfront. It proved that the local People's Committee planned this road for use by its citizens. Apparently more political-context-knowledge is needed to understand tourism practice. In this article a reflection on this contextual approach will take place as it grew out from within the development of this educational practice. First, the theoretical background of this reflection will be explained. Then the history of this practice will be depicted backwards from the point of view of where it stands now. Last, a critical reflection will take place in which an attempt will be made to evaluate the additional value of this contextual approach.

\section{Theory and Practice: The International} Classroom as a Praxis

Contextual education starts from the complexity of our network society (Appadurai, 1996, 2001; Castells, 2000; Hannerz, 1993). An educational program has been developed at NHTV that has its roots in this new emergent society. This international program was developed in a piecemeal, "incremental" manner since the 1990s in a collective effort by different stakeholders: lecturers, students, and the tourism industry. From the start its main study object has been the international tourism destination, where various interfering networks of a diverse composition come together. In the first half of the 1990s the accent in the program was on the planning and development of international destinations. The destination was seen mainly as a product and students were taught to become consultants in these international tourism destinations. At the start a 1-week excursion was added in the second year program with lectures at the destination organized by the ITMC staff. During the program the students would be provided with the necessary tools that consultants need in their profession. One might call this approach an instrumental one. A crucial breakthrough in this educational philosophy has been another perspective on what the excursion signifies in this curriculum. Instead of an excursion, the concept of fieldwork was introduced. In this concept students were supposed to make an analysis of the international destination during 1 week of introductory lectures in the destination and 2 weeks of work in groups of international students on a destination analysis on different places of the destination. In order to do this properly the decision was made to add international marketing and cross-cultural studies as two main perspectives, additional to tourism planning and development. Characteristic for these changes was the change in the crosscultural program. Starting with general descriptions of the culture to be visited by using Hofstede's frame $(1980,1994)$ that seemed to explain "whole cultures" with four to five dimensions (Platenkamp, 2007), it gradually became clear that this frame was not enough to open up the students eyes for the cultural specificities of the destination concerned. A choice was made to introduce a contextual approach with which students were supposed to dive into the cultural context in order to get at information in their destination analysis. This contextual approach stimulates students and lecturers to listen to "the otherness of The Other" in the subtle tension between "Self and Other" and to study the economical, political, and cultural environment as a crucial context for tourism development. Gradually the instrumental approach changed into a contextual one. Gradually an environment has been created and is ever changing and adapted to differing circumstances in a continuous process with people who are searching for inspiration in the theory and practice of international tourism destinations. In this inspirational environment the stakeholders involved try to create a "third space" (Bhabha, 1994; Hollinshead, 1998). In this third space there is a need for a theory of 
hybridity (Hollinshead, 1998), in which room will be made for new, emergent voices, and the "translation" of social differences that goes beyond the polarities of Self and Other, East and West. In a postcolonial "order" this also implies that previously silenced or silent voices enter the academic and professional discourses from their local perspectives in between the global and the local, from many in-between worlds. In a third space, therefore, different traditions meet with their fusing, clashing, or interacting visions on moral and existential themes that are often excluded from official discourses.

That the horizon of a third space in itself makes sense becomes clear in Said's (2003) quote from Orientalism: "Perhaps the most important task of all would be to undertake studies in contemporary alternatives to Orientalism, to ask how one can study other cultures and peoples from a libertarian, or a nonrepressive and nonmanipulative, perspective" (p. 24).

In a third space one tries to reach beyond distinctions between gender, class, race, or nationality. Local practices that support this type of discourse support a principle of hope in a complex and often hostile world of many cultures. A third space is like an empty paper that stares at you before you start to write. It has been associated with frustration but also with an enormous stimulus for creativity.

This all looks like a beautiful theory perhaps, but in practice things go "wrong" all the time. However, in this emergent practice most participants noticed that taking care of the contextual complexity of this practice self-evidently led to the need for a more sophisticated theoretical approach as well. To imagine a "third space" as a guideline in this theoretical orientation also appeared a logical consequence. From within this educational practice the international classroom could be imagined as a "praxis." Instead of the (Marxist) class struggle as main orientation of this theory-impregnated practice, a "third space" became the theoretical guideline. In a third space (cultural) differences are articulated that may open:

the way to conceptualising an international culture, based not on the exoticism of multiculturalism or the diversity of cultures, but on the in- scription and articulation of culture's hybridity. To that end we should remember that it is the 'inter' - the cutting edge of translation and negotiation, the in-between space-that carries the burden of the meaning of culture. (Bhabha, 1994, p. 38)

In tourism this idea has been introduced in a balanced and elaborated manner by Hollinshead (1998). Also in a noncultural sense this concept implies that participants in this praxis are used to look at different perspectives-for example, on what a destination is - and continuously change perspectives on destinations as well from the point of view of different stakeholders.

Starting point for this praxis of contextual approach is the tacit knowledge that resides in the contexts that people carry with them in their encounters. These encounters take place in various interacting networks from all over the global village that constitute the frame of any international but local destination. This intriguing tacit knowledge inspires participants in this international classroom to develop manners that generate this knowledge to the surface and subsequently to involve it into relevant practices at the international destination. When, like in March 2007, students on Bali perceived the enormous amounts of garbage washed ashore at the beaches, their first reaction was predictable. They almost all had the tendency to presuppose a Western superiority in ecological consciousness based on the impossible destruction of these beautiful beaches. But then they were asked to dive into the context of Balinese attitude towards nature. They found that in Bali Hinduism beautiful sceneries are associated with the highest mountains, where the good spirits live. In the architecture of their compounds Balinese people construct their living rooms or their house-temples in the direction of the highest mountain of Bali, the Gunung Agung. The toilet is situated to the seaside. In the sea the evil spirits dwell in eternity. Spirits should be respected but they are not associated with the beautiful images Westerners often have of beaches on the beautiful seaside. Therefore, garbage on the beaches is no big deal for the Balinese. In the meantime, this careful dive into the context of Bali Hinduism provided us with some very relevant information of the refined way the Balinese people themselves 
think about inter alia the relation of man towards nature. Professionals in the hotel sector took this knowledge seriously and developed Green Hotels on Bali in which the basic principles of Bali Hinduism were included in their concept: this is exactly how tacit knowledge can be generated to the surface and be used in professional decisions.

For the contextual praxis of the International Classroom this implied two main phases:

1. a phase of contextualization in which this tacit knowledge needs to be generated to the surface: Why was this garbage on the Bali beach?

2. a phase of decontextualization in which this knowledge has to be put on the agenda of relevant discussions.

In phase 2 a structured approach in the international classroom is needed in order to clarify the type of discussion that will be challenged. Gibbons et al. (1994), Tribe (1997), Lengkeek and Platenkamp (2004), and Platenkamp (2007) have introduced an extra mode of knowledge apart from the academic one that we know since the end of the 17 th century. In this book the authors discuss the transformation in the mode of knowledge production as a global phenomenon. Alongside "traditional" modes of knowledge production (mode 1 knowledge) a mode 2 knowledge emerges created in a broader, transdisciplinary social and economical context of application. It has been called mode 2 knowledge because the authors deem the conventional terms such as applied science, technological research, or research development as inadequate.

Apart from these two modes of knowledge, however, mode 3 knowledge has been introduced by Kunneman (2005) (see Platenkamp, 2007) in the awareness that in both other modes there is a long-term tendency to exclude the "slow questions," narratively related to sickness, death (colonial!), repression but also to moral virtues like compassion, inner strength, or wisdom and other sources of existential fulfillment that remain crucial for all generations in various places. Kunneman calls inter alia for a relatively autonomous contribution of the treatment of these slow questions to professionality in general.
NHTV Breda Revisited as an Inspirational, Mode 2, Praxis

In this concept of the international classroom as the evocation of a third space important roles have been attributed to students, lecturers, and stakeholders. They all are challenged to contribute optimally to the education in and to research on international tourism destinations. Especially the research part in this statement still has a long way to go, but there are serious steps taken to make it as flourishing as the educational practice itself. As for the educational practice the situation is inspiring. Strategically positioned people "with vision" in the tourism practice have been proven to be attracted to this educational practice and on their turn are inspirational for the other stakeholders as well. From within the educational constraints in the international classroom one looks for opportunities that have more perspective, for unusual stories that are needed but not obvious at first sight.

In this type of education the aim is not to produce standard products in standard cooperation. For example, the end products at the fieldwork are based on a flexible way of working right from the start. In this starting phase students often do not know what it is all about. Their assignments are not yet that structured; they have to look for their own ways of working in order to understand the situation in the international destination to be analyzed. Of course, they will have regular supervision. But also during this supervision questions are raised at the start instead of answers given. From the stakeholders involved the same attitude goes without saying. In this manner flexibility and diversity of positions and perspectives are taken as a point of departure. Diversity is needed, of course, because no consultant can afford to jump to conclusions in this starting phase. First one needs to let "the situation speak for itself" and to try to understand as much of the complexity and diversity of the situation as possible. Here too, the accent on contextual understanding speaks for itself.

Stakeholders involved address one another in this same mentality in theory and in practice. This mentality also proves to be contagious. Participants feel themselves challenged and appreciated because they are addressed to in their unique qualities that will be confirmed in this process. At the 
same time they perform in cooperation and strive to come up with something special at the end of the day. It often leads even to more personal contacts in various gradations, probably also because people feel attracted towards one another in this same, inspirational climate. People start to have an intrinsic interest in each other and in the uniqueness of the work of the other. For managers this often includes an extra quality. Many managers seem to have lonely jobs and appreciate this intrinsic interest from within this inspiring educational practice. They are eager to contribute to the processes in this practice by delivering inspirational lectures or by challenging dialogues in a self-evident manner.

The crucial point here is that this whole practice has been framed within the international classroom. The practice of the international classroom mixes with tourism practice in international destinations in an inspirational manner and with mutual respect. Their own actions in practice are put into a broader perspective and professionals try to let education think with them, which inspires again both parties. There is always a story behind professional activities that people want to share. In organizations one can try to address the people who feel inspired by these stories and who feel the urge to add their own stories to it, to structure their thoughts also when things are not yet clear enough, and to reflect on the essences of situations. This happens mainly because the tone has been set in the international classroom, because the whole context invites people to do so.

The fieldwork (March-April 2008) of second year students in Cambodia and Vietnam serves as an illustration. Staff members have assembled much material on both countries by concentrating in the explained manner on diverse perspectives on these emerging and developing countries. Looking at the dynamism of the actual situation and persistently concentrating on the complexity of the context are some of the basic elements in this starting phase. Many conversations were organized with different stakeholders in which implicit and often tacit knowledge was focused on. A growing involvement has been created from these different stakeholders; many perspectives on some main issues in these turbulent societies were in- cluded and in this sense the general climate of an inspirational educational contact is on the move.

\section{Contextual Higher Education in Tourism:} An Illustration

Ten years ago ITMC decided to take all of its second year students for an extended fieldwork period of 3 weeks on location, as an integral part of the academic curriculum of international tourism management. The first location was Bali, where students were introduced to a variety of stakeholders of the destination in the first few days. Then, for over 2 weeks, they went to their assigned areas in smaller groups, and lived there, for the purpose of research, immersion, and understanding. The following years' destinations like Phuket, Koh Samui, and Bali again were visited repeatedly.

In March 2008, 10 years later, a combination of two "new" destinations was proposed to 155 second year students: Siem Reap in Cambodia and the Central Coast of Vietnam. The original educational concept - contextual-could be further developed and strengthened in these contexts new for both students and staff.

The concept of this fieldwork as a component of the ITMC curriculum is to create and make use of complex cultural environments-complex for foreigners - as a learning environment for students. It is situated at an early stage of their studies, second year, whereby a certain openness and "fresh" approach is expected and encouraged. The students' discovery process of what happens in and around tourism destinations forms the main substance of the final report: their destination analysis. The idea is that students in this stage are less obstructed and bothered by "instrumental" tourism concepts and frameworks.

The project set up stimulates the enhancement of context awareness. Students from a variety of backgrounds, and many of which do not originate from the destination visited, bring, within them, their own contexts, their own learning resources, valuable for themselves, for their fellow students, but also for the teaching staff. The awareness of their own contexts increases significantly while living and researching in another context. It is this interest for these contexts, the unfamiliar one as 
well as their own, that lies at the heart of this discovery project.

\section{Contextual Approaches in Education:}

\section{"Contextual Sensitivity" in Business Practices}

The contextual approach departs from the idea that many relevant insights in the study objectfor example, a tourism destination - may be found in unwritten or implicit types of information. Existing frameworks of tourism destination planning and development, as well as destination marketing or tourism impacts studies, when used to set up research about a given destination, will provide ideas for topics. They also provide the illusion that once information about these topics is obtained, one has all the relevant insights in the destination. Examples of these topics are: a master plan or a regional development plan; a destination value chain report; a marketing plan for a hotel; figures about beds, overnight stays, and arrivals.

It is remarkable that the majority of students carrying out this required field research tend to lean on said tourism destination frameworks and "common knowledge" about tourism and development as propagated by media and popular culture and education. They will set up a plan to gather this information, hopefully confirming these preexisting assumptions, and be satisfied when they collect it.

A contextual approach makes this type of information more secondary, more subordinate. In a contextual approach students are encouraged to start by —as much as possible-leaving their frameworks behind. Simultaneously to having preconceptions and stereotypes about tourism development, these students are very open to new information and new situations. The choice to carry out this fieldwork in a place unfamiliar to most students (Southeast Asia) has to do with this contextual approach. The new situation is often so overwhelming and full of new impressions and information, and coming from all and unexpected directions, that the theoretical tourism frameworks not yet firmly rooted, have to make room for this new experience. Also, the not yet firmly rooted frameworks and preconceptions are touched or disturbed. Students become more aware of them. We call this perspective the "self-reflexive" per- spective. This is a necessary step in the opening up to new situations and for the development of new insights.

In addition to actively using this phenomenon of "being overwhelmed," the contextual approach also encourages students to open up to it further. Students' observations, their encounters with the people they meet unexpectedly or without a study purpose, but also their diaries, emails, and text messages they send home, these all become part of the field research. These become valuable primary data that form the starting point of their further research. In fact, often without knowing it, they are creating their own frameworks, with specific relevance to their assigned study areas.

The second year 3-week fieldwork project, pivotal to the entire semester and to the three disciplines taught (market analysis, tourism planning and development, and cross-cultural studies), creates a unique space in which the context plays a key role, and where students are encouraged to apply and develop their sensitivity for the context of their study object: the tourism destination.

On the Central Coast of Vietnam, three destinations were selected for students: Hoi An area, Da Nang area, and Hué area. Students were divided in groups of 10 and assigned one area belonging to one of these three destinations. For their own study area, they have the opportunity to experience and observe all the ins and outs of a real-life tourism destination. The idea is not only to simply "apply taught theory," but more importantly, to learn to look, see, and observe. At the end of the day students learn to do research in a contextual manner.

Organizing the fieldwork project in Vietnam, after a first stop in Siem Reap, Cambodia, meant putting more demand on the contextual aspect of the assignment. On developed destinations like Bali or Phuket, where we had mainly been in previous years, tourism dominated the scene. Tourism was the context and the context tourism, so it seemed. Though disturbed by the bombings on Bali, and the tsunami on Phuket, the position of tourism was established. Students interviewed tourism stakeholders and had access to ample tourists, of which a substantial proportion were repeat visitors.

In Vietnam, tourism is more a matter of the 
future than of the past. Much of what is happening exists in the form of plans or merely ideas and expectations, which are not being disseminated in a formal, scholarly way. Studying tourism in the Central Coast area had to do for an important part with foreseeing, looking for visionaries, extrapolating carefully based on the few visible indications of the speedy developments taking place.

Studying tourism development in Hoi An, Da Nang, and Hué also implies paying greater attention to the society, to the people living and working in agriculture, fishing, and industry, their past, and their priorities today. In Vietnam, the broader context in which tourism development takes place is more present, and even easier to access sometimes, than evidence of tourism.

One group of students was assigned part of Da Nang's coast area. This group was composed of Hungarian and Dutch students, each having their experiences and expectations of a holiday on the coast. Da Nang coast area, including the famous (for Westerners) China beach, was nothing like they had expected. Their area hardly resembled a beach resort for them, and it was used primarily (above $95 \%$ ) by Vietnamese inhabitants of $\mathrm{Da}$ Nang. This had many consequences for their field research as well as for the research skills needed to fulfill the requirements of their assignment. How can one understand the ins and outs of this destination if one has no "international tourist" to interview? How to understand the operations and strategies of hotels if there are no expats or no international (read Western) establishments? Almost all stakeholders appeared to be local, and English is not their working language. The context, the Central Vietnamese context of work and leisure, became their main study object. This group addressed their challenges in a remarkable way. They were "condemned" to use a powerful technique for the contextual approach: observation. Students tend to underestimate this technique or consider it a lesser one in comparison with making surveys or collecting statistics from immigration or tourist information centers.

The example of the Danang Coast group suggests that areas dominated by domestic rather than international tourism are more ideal for the contextual approach. This is not necessarily the case. For the students it was a valuable realization that their specific area was a reality for many tourism destinations in the world and that these areas can coexist alongside more internationally oriented areas. On our first staff visit to this group, when they had explored the area for 2 days, one student expressed her astonishment about this: "Why is it not being developed here (for international tourism), with such an attractive beach, while it is being developed on almost all strips on the beach on both sides of Danang?" Such a question allows for further exploration in at least two directions: 1) on a more microlevel, to look more closely into factors that define the allocation of places to foreign tourists, and 2) her acceptance that this area is totally different from the student's expectation of a coastal destination paved the way for a more open approach of the area.

For a contextual approach it is also necessary to allow for chaos, to have students look around without starting their "formal" research. They should be allowed to slow down, to note what they perceive as contradictory, what they do not understand. They have to sit in a variety of places at various moments of the day, they have to listen to what people tell one another, or-if they do not understand the language- - how they tell, and wonder about what they could be communicating. The first of several staff visits is programmed in such a way that the students' first impressions and experiences define the agenda, and most probably the research plan for the time remaining.

It is striking how care and attention is needed in this first phase of field research, or else students (and staff) would pass by what is really going on, below or even on the surface, disregard it, and look for what they expected. This is a common failure of professional consultants.

The 2008 fieldwork was organized in such a way that students arrived in Siem Reap Cambodia. This arrival symbolized for many students their "arrival in Asia." The 5-day program in Siem Reap had to leave room for students' own initiatives and discoveries, after a proper "acclimatization." Students did not have an assignment for these 5 days, other than an account of their first impressions and of a selection of their encounters with people living and working in Siem Reap. These encounters were unplanned or unexpected 
encounters; they did not have to make appointments or look for specific information.

Before leaving Siem Reap, students were convened in groups of about 35, for 1.5 hours to discuss their experiences. This discussion was set up to leave room for expression of surprise, frustration, astonishment, or unprocessed information. The last half hour was reserved for questions about tourism development. This was a new experiment in contextual approach. We wanted to see what students had picked up of what they saw, and how they could formulate this in terms of tourism development, without having looked for it. Results of this approach will be elaborated on further down when we look into the added value this approach can have on the study and development of destinations. For now there are two points to be made regarding this experiment:

- The 5-day period in Siem Reap, with an open assignment to look around and experience, appeared to be a warming up for the actual destination analysis exercise on the Central Coast of Vietnam. First meetings with students showed they had gathered an impressive amount of observations and first astonishments, leading to a variety of research directions for the 19 destinations in Vietnam.

- This discussion also revealed the tension between the open assignment calling upon broad minded and open discoveries about people and places on the one hand, and the existence in students' minds of preconceptions, whether theoretical or other, on the other hand. We will see later on that this tension leads to an important additional added value of this form of education, which is the realization, or conscious awareness of, these preconceptions, stereotypes, and assumptions.

\section{Evaluation of the Contextual Approach}

By embedding higher education in international contexts one introduces the complexities of the "hidden dimension" (Hall, 1969) and the tacit mysteries of different interpretive traditions from all over the world in confrontation with globalizing developments and thoughts. It implies that multicultural resources, value systems, or world views are supposed to be connected in an inclusive perspective on tourism destinations. In this perspective attention is needed for the other; room must be created to the human quality of looking at the world through the eyes of another.

In the interpretive tradition of the social sciences this principle has been elaborated inter alia by Clifford Geertz (1983) with his "hall of mirrors." In everyday situations people enter this "hall" and start to interpret each others' behaviors by reflecting and then reacting to the interpretations of the others. Although this image must be seen as a precondition to any understanding in this field, it does not seem to be enough. The problem with mirrors is the threat of narcissism. Therefore, a stimulating space should be created-a third space-where the relation between Self and Other becomes a complex one that can be hardly understood by one "self" and that in any case needs the utmost openness, receptivity, and criticism that Said (2004)) also asks for.

With this awareness in mind the contextual approach stimulates all its participants to be patient, to listen, and thus allow themselves to be slow if needed. When in a mode 2 discussion solutions are sought for in dealing with existential questions of life and death, slowing down is needed in a mode 3 discussion where a dialogue and learning process will be the guiding principle. It demands from the participants all the qualities that have been mentioned before in this crucial and thrilling relation between Self and Other. After such a learning process one might expect that solutions in mode 2 will be of a much more "sustainable" nature in this complex network society.

\section{Results}

Striking in student and staff findings in the field work project are: (a) discovery of the value of listening to the other (at a slower pace) for one's own development, for the group process, and for understanding the dynamics of the destination; (b) the specificity of contexts in which tourism development takes place and also the way this specificity defines tourism development; and (c) derived from the precedent point, the questions and critical stance towards mode 1 type tourism knowledge. These findings will be developed and explained further here below. The three conclu- 
sions can be subdivided in the following observations. The first two observations are related to the first conclusion; the other ones to combinations of the last conclusions.

\section{Learning to Listen}

When asked to reflect on personal contributions to the group process, several students formulated their contribution to the group in terms of their listening skills. Their contribution to the group process was to listen to the others. Coming from students having been raised in a Dutch (educational) culture this is all the more striking because the accent there is to make yourself be heard: a quiet person in the group is often seen as mysterious or dubious.

Many students reflected on their lacking patience as a weakness: in multicultural teams this seems all the more necessary. Their learning point thus became to be more patient and allow for discussion and deliberation, even though their wish was to get on with the assignment. Several reports showed this had an added value to the result in the end. The best performing teams were those who connected their multicultural resources.

\section{Discovery of People's Pride}

In students' written reports and individual assignments related to the destination analysis, the presence and intensity of local people's pride is remarkable. There are two ways to approach this finding: (1) a need arises to look into why students find this remarkable (self-reflexivity on one's neocolonial or ethnocentric worldviews), but also (2) interesting to look into further is this very pride, what it covers, and from there, what are local inhabitants' worldviews?

Ambiguous perhaps is that simultaneously students reported a feeling that local people looked up to them. Can this lead to a refreshed, real postcolonial discussion in tourism replacing the still influential neocolonial discourses?

International tourism developments are shaped and formed as a result of international and internal relations of power. The relations between countries that are donating and receiving capital flows determine the course of tourism developments in beneficiary countries. A greater variety of voices are drawing attention to this and requesting research and discussion.

Jeffrey Sachs from the World Bank and Joseph Stiglitz, now professor at Stansford University, both contributed to the discussion about globalization and the specific effects on economic and social developments at regional and local levels. They demonstrate the necessity for a much more specified approach of developments at local levels, also demanding much better knowledge and understanding of local contexts.

This leads to the next two sets [see (b) and (c) above] of findings resulting from the praxis of contextual approach in tourism education.

\section{The Need to Rethink the Role and Position of "Local Communities" in Tourism Planning and Development Models}

In models of tourism development the local inhabitants, often referred to as "community," remain either implicit or ill understood. They are sometimes situated in a destination framework, sometimes even totally absent in market-productcentered destination mix models like in Mill and Morrison (2006) and Cooper, Fletcher, Fyall, Gilbert, and Wanhill (2008).

Tourism frameworks and concepts seemingly force us to look at destinations "from the outside." One could imagine, however, to turn things around: first there are inhabitants, entrepreneurs, governmental authorities, etc., on which tourism starts to take a position, defined by a variety of also local stakeholders, with a variety of interests.

The contextual approach described above leads to a stronger understanding of this diversity, and also of the relative influence of each of these local stakeholders. While various tourism discourses suggest otherwise, this influence is at least as determining for the course of development as, for example, a large foreign tour operator or an airline company.

\section{The Debilitating Impact of Impact Studies on the Understanding of Tourism Development}

A critical approach of the instrumental concept of impact studies has been brought forward by Meethan (2001) and Hollinshead (2007). Meethan is "particularly eager to reject analyses of tourism 
which have been patronizingly framed around the twin supposition that firstly tourism is always an external (i.e., impacting) agent of change. And secondly, he repudiates analyses of tourism which bolster the view that receiving destinations/receiving populations have always hitherto possessed 'cultures' that have been (before the onset of tourism) essentially unchanging lacking any internal dynamism of their own" (Hollinshead, 2007, p. 175). An instrumental application of impact studies results in a rather sterile listing of positive impacts on the one hand and negative impacts on the other. Meethan calls for a reframing of the questions that are asked in Tourism Studies about the relationship between tourism, globalization, people, and place. But these revised forms of thinking, the more reflective, interpretive, contextualized, audience are penetrating only slowly (Harris, Wilson, \& Ateljevic, 2007).

In Central Vietnam students are at first appalled when they hear about the relocation of villages in Cua Dai. However, during their research students found evidence of a broad variety of reactions of residents and villagers to these relocations. Villagers who are being relocated expectedly would be very unsatisfied with tourism and the outside world imposing this upon them. It appeared, however, that some, younger generations, in part, saw an opportunity in this, to open up a shop with the indemnities obtained. It appeared also that others, older generations in part, were satisfied and optimistic with the broader context in which these developments were taking place, namely Vietnam opening up to foreign influences and the creation of opportunities for trade and investment. Their relocation, they said, was to be situated in this broader development of Vietnam, which is a good thing they found.

Also the displacement and or demolition of graveyards in the beach development areas between Danang and Hoi An for the purpose of building resorts provoked contempt among the students at first. Students thought this a clear case of demolition of local culture and found it no good to have local cultural heritage make way for spoiled tourists from the West. However, reconsideration and immersion lead to new insights. Students were asked to reflect upon their own contempt: why this contempt? What does a graveyard mean for them? In their context? Then they were asked to go back to their area and find out what these graveyards mean to the people living there, to the investors, to the People's Committee, and to other authorities. The same ideas about progress proved to live considering the digging up of graves as to the relocation of villages.

So a contextual approach allows for a scope more embedded in a broader context from which issues arise. Such issues are then studied "from within" in all its complexity. This approach therefore leads to insights before neglected, oversimplified, or even distorted by the instrumental approach of a social impact study.

\section{Looking Beyond the Exact Definition of the Destination}

One group of students was assigned the $\mathrm{Xa}$ Cam Thanh area in Hoi An. At first it seemed an area with little evidence of tourism development. At second sight, a movement of local inhabitants was noted; people were moving out of the central area of Hoi An, to this area. It appeared to be an overflow area for other more developed areas. Local inhabitants making money in tourism were (re) building their houses there. This area, with hardly any evidence of tourism development, appeared to be an area in transition due to tourism development in the surrounding areas. Around Hoi An as well as Da Nang, we could identify more such locations.

The beach strip from Hoi An to Danang is now gradually providing tourists with more luxurious beach resorts. Tourism wisdom teaches us that tourists stay inside these resorts, barely leaving the grounds or interacting with surrounding local inhabitants. However, we saw them walking, leaving the area, over the beach, and wander to the local areas, where Da Nang citizens recreate in their own way. These tourists visit the restaurants on the beach primarily set up for local people and occasionally for organized tour groups. Then they return to their luxurious resorts. What does this mean? What are consequences for the areas, both of where tourists are staying and where they are not? These kinds of questions can be raised and partly connected to Sheller and Urry's (2004) 
point made in Tourism Mobilities, that places are in play and places are at play.

Such findings were possible by taking notice of what was happening in the surrounding areas. Then, a connection can also be made between what is happening on a microlevel, with what is happening on a regional, national, or even international level.

A destination is not primarily a geographical entity, but it is the combination of meanings people attribute to it (Ashworth, Tunbridge, \& Graham, 2007) and functions like tourist historic cities, shopping, leisure, and residential areas (Ashworth \& De Haan, 1985). Insight in tourism market and business perspectives on the destination is necessary, in addition to local and foreign planners' perspectives.

\section{The Meaning of Destinations Is Different}

for Each Perspective: The Implications and Hopes Invested in Developments Are Different for Everyone

In Vietnam the People's Committees deliberate over the interests of the people and try to protect their interests, seeking balance between revenues and public values. The great variety of investors shape the area having their interests in mind: they lobby for more accessibility and participation in destination promotional discussions. Local entrepreneurs also see opportunities in setting up businesses further complementing developments initiated by the government and Viet Kieu (Vietnamese diaspora) and foreign investors: the numerous laundry facilities, small restaurants, and food and beverage hawkers are evidence of this.

Each of such interest groups sees development opportunities in the same areas and plan and develop this "opportunity space" accordingly. Different stakeholders therefore create and work on their own "destinations" independently at the same destination in the same area as other stakeholders do, almost as if acting in parallel universes.

Tourism development in Central Vietnam could have been studied using existing planning models, "objectively," revealing step-by-step developments taking place, but a contextual approach clarified that destination development is something different for each investor or stakeholders group. The result of such an insight in a destination can lead to a diagnosis and then strategies that combine these different existing parallel realities. Measures recommended will be more effective because they are more embedded and relevant for the issues on the ground.

An Organic Approach to the Study of Destinations Using Instruments for What They Were Meant for: "Theory" Rather Than "Checklists"

At times during the process, as well as afterwards in the reporting phase, we were wondering whether we should even remove certain tourism concepts (we call them instruments) from students' curriculum. It seems like "destination mix," for example, stands in students' way for a better more "holistic" understanding of their area. It works, like previous examples on impact studies, in a debilitating way and it makes the overall product students present weaker. Students are often well apt to discover things, sense opinions or ambivalence in attitudes, and this all has no place in a "destination mix" idea in which tourism markets as well as local perspectives are stunningly missing.

Another example is Butler's "tourism area life cycle." The limited possibilities to characterize an area through this model lead to difficulties for some student groups. Stating their study area was in a growth or development phase contributed very little to the understanding: it captured so little of the complexities of the destination's realities. When students were asked what they would do if they did not have "Butler" at hand, they were awestruck. Subsequently this group remained somewhat stuck. Using such a model, we felt, stood in the way more than that it supported students' understanding process.

\section{Critical Note}

Over the past years, we have come to realize the sometimes suffocating impact of current tourism frameworks. The contextual approach gives students, researchers, and practitioners the room for relevant insights and knowledge, otherwise masked or obscured by said frameworks. This re- 
view article illustrated the workings of this approach, as well as some of its results.

Simultaneously a critical attitude remains a priority. The "dream" of creating spaces where students and researchers can uncover dynamics and developments is one we keep striving for. Also, these close encounters, and related discoveries should also lead to better discussions and other solutions for developments.

The insights and understanding gained in the analysis phase of the destination analysis lead to open ends. Many issues are raised and identified, and need to be taken a step further both in terms of research and in terms of education. The new or other insights gained need to be evaluated, and their implications discussed. In the coming years the results in education also need monitoring with questions like: "To what results do these insights lead in terms of product development ideas or innovation" or "What recommendations are more suitable and preferred when looking at the variety of local perspectives?"

There is also the realization that the contextual approach to education provides no easy or comforting blueprint. There are alternatives, of course, to reach the objective of a greater understanding of our "creolizing world in between the global and the local." A wider identification of these alternatives and study thereof will undoubtedly lead to improve and refine the contextual approach.

Finally, this approach does not replace or reject all instruments critiqued in this article. Some instruments remain very useful when situated in context adequately. Planning theories, stakeholder analyses, concepts like organic and induced images, or the experience dimensions of tourism destinations are only a few examples.

\section{Conclusions}

Practices in tourism education in a globalizing context gave way to the "international classroom," "a symbolic space in which a rich, complex and local, international practice to be explored, enunciates new and promising areas in tourism education and research" (Lengkeek \& Platenkamp, 2004).

This idea has been considered useful as a foundation based upon which a contextual approach of higher education in tourism could be introduced and developed. The main aim of this review article has been to discover this space as an educational space, where cross-cultural contextualization of life world knowledge and the translation into mode 1 , 2 (and 3) have been the guiding principles. These principles have been put forward because of the fact that they seem to be a right answer to the lack of understanding in our "creolizing world in between the global and the local." In tourism and leisure discourses too often simplistic theories dominate where nuances and refinement in the (cross-cultural) analysis are needed. Through the organization of the international classroom as an evocation of a third space a serious attempt has been made to give a sophisticated answer to that need. This educational practice promises to be a stimulating one that may serve as a mirror to other practices in this field. Students who have had their "Bildung" in this space are supposed to have had an ideal preparation for these other international practices in tourism and leisure. On the other hand, the guiding principles of this space are designed in the first place in order to be able to contribute in an optimal manner to the necessary research of mode 1, 2, and 3 in the area of tourism and leisure studies.

This article then analyzes the contextual approach using illustrations of educational practices at NHTV, primarily the fieldwork-oriented semester of second year students studying the tourism destination. Then, the article sought to elaborate on the added value of this approach.

\section{References}

Appadurai, A. (1996). Modernity at large: Cultural dimensions of globalisation. Minneapolis: University of Minnesota Press.

Ashworth, G. J., \& de Haan, T. Z. (1985). The tourist historic city, a model and initial application in Norwich, $U K$. Groningen: GIRUG.

Ashworth, G. J., Tunbridge, J. E., \& Graham, B. J. (2007). Pluralising pasts: Heritage, identity and place in multicultural societies. London: Pluto.

Bhabha, H. K. (1994). The location of culture. London/ New York: Routledge.

Foucault, M. (1977). Surveiller et punir: naissance de la clinique. Paris: Gallimard.

Geertz, C. (1983). Local knowledge. Further essays in interpretive anthropology. New York: Basic Books.

Gibbons, M., Limoges, C., Nowothy, H., Schwartzman, S., 
Scott, P., \& Trow, M. (1994). The new production of knowledge. London/Thousand

Oaks/New Delhi: Sage.

Habermas, J. (1982). Theorie des kommunikativen Handelns. Frankfurt am Main: Suhrkamp.

Hall, E. T. (1969). The hidden dimension: Man's use of space in public and private. New York: The Bodley Head.

Hannerz, U. (1993). Cultural complexity. Studies in the social organisation of meaning. New York: Columbia University Press.

Harris, C. Wilson, E., \& Ateljevic, I., (2007). Structural entanglements and the strategy of audiencing as a reflexive technique. In I Ateljevic, A. Pritchard, \& N. Morgan (Eds.), The critical turn in tourism studies: Innovative research methods. Amsterdam: Elsevier.

Hofstede, G. (1980). Culture's consequences: International differences in work-related values. Beverly Hills, CA: Sage.

Hollinshead, K. (2007). Worldmaking and the transformation of culture: The enlargement of Meethan's analysis of tourism and global change. In I Ateljevic, A. Pritchard, \& N. Morgan (Eds.), The critical turn in tourism studies: Innovative research methods. Amsterdam: Elsevier.
Kunneman, H (2005). Voorbij het dikke-ik. Amsterdam: B.V. Uitgeverij SWP.

Lengkeek, J., \& Platenkamp, V. (2004, May). The international classroom of tourism studies. Paper presented for an International Conference for Sociologists on Lesbos, Greece.

Meethan, K. (2001). Tourism in global society. Hampshire/ New York: Palgrave.

Murphy-Lejeune, E. (2002). Student mobility and marrative in Europe. The new stranger. London/New York: Routledge.

Mill, R. C., \& Morison, A. M. (2006). The tourism system. Dubuque, IA: Kendall/Hunt Publishing Company.

Platenkamp, V. (2007). Contexts in tourism and leisure studies. A cross-cultural contribution to the production of knowledge. Wageningen: Wageningen University.

Said, E. (2003). Orientalism. London: Penguin Books.

Said, E. (2004). Humanism and democratic criticism. New York: Palgrave/Macmillan.

Sheller, M., \& Urry, J. (Eds.). (2004). Tourism mobilities, places to play, places in play. London: Routledge.

Tribe, J. (1997). The indiscipline of tourism. Annals of Tourism Research, 24(3), 638-657. 